\title{
DIE WESE VAN DIE KERK VOLGENS CALVYN.
}

\section{Inleiding.}

Die leer van die kerk by Calvyn is een van die gewigtigste en verreikend. ste stukke in die hele Calvinistiese sisteem. Daar was seker geen enkele saak waaraan Calvyn meer aandag gegee het en wat hom nader aan die hart gelê het as die herlewing van die idee en die praktyk van die ware kerk nie. Dit is met reg beweer dat die groot doel van sy lewenswerk was om hierdie idee te realiseer ooreenkomstig die suiwere patroon wat deur die Skrif geleer word $^{1}$ ). Sy werksaamheid in Genève en na buite was voor alles gerig op die herstel van die kerk ooreenkomstig die instelling van Christus. Vir die selfstandigheid van die kerk, vir die onafhanklike uitoefening van die tug deur die kerk, vir die suiwerhou van die bediening van Woord en Sakramente het hy jarelank moeisaam en tot die oorwinning toe gewerk, gely en gestry.

\section{Die oorsprong en fundament van} die kerk.

In die middelpunt van die teologiese denke van Calvyn staan God. $\mathrm{Hy}$ is genoegsaam in Homself maar tog het dit Hom behaag om Homself te openbaar en om na die sondeval vir Homself 'n volk te vergader uit die hele menslike geslag. As ons gaan handel oor die kerkbeskouing van Calvyn is dit van die allergrootste belang om hierdie teosentriese uitgangspunt te benadruk, want daarin reeds onderskei hy hom al van die teologiese sisteem van Rome, wat in sy wese antroposentries is en van 
Luther, wat hoofsaaklik soteriologies is.

Die diepste oorsprong van die kerk is dus die raadsplan van God. Die kerk rus op die ewige predestinasie en kom uit die verkiesing op. Die oorsprong van die kerk is alleen te soek in die soewereine welbehae van God. Die kerk is die verwerkliking van die goddelike besluit, maar ook is dit die middel waardeur God ons tot die gemeenskap met Christus roep en hou.

Aan die ander kant beklemtoon Calvyn dit dat die kerk gebou is op Christus. Christus is fundament, uiterste hoeksteen, en Hoof daarvan en tot Sy amp behoort die beskerming en opbouing van die kerk. Op 'n ander plek sê hy ook: Christus is Koning van die kerk, haar Wetgewer, haar Regter. Hy skryf die wette voor, waaraan sy haar moet onderwerp.

Op grond hiervan beskryf hy dit as dubbele dwaasheid dat die Roomse Kerk die Pous verhef het tot hoof. Daardeur word die orde wat God gestel het tussen die Hoof Christus en Sy lede omgekeer. Dit is dubbel dwaas om 'n steen wat op die fondament behoort te rus, tot fondament te maak. In een van sy briewe skryf Calvyn: Die Pousgesindes het met snode geweld die Hoof van die liggaam afgeskeur en op die wyse die kerk tot 'n romp gemaak. Hoe kan Christus dan nog Hoof wees as Hy van alle werksaamheid beroof, van alle heerskappy uitgestoot en van alle eer ontbloot is?

III. Die Kerk as liggaam van Christus.

In sy Institusie bestee Calvyn baie aandag aan die behandeling van die werk van Christus. Die verdienste van Christus kom egter Sy volk ten goede.
Dit geskied deurdat ons met Christus saamgegroei is deur die geloof. Deur die geloof neem ons Christus aan en alles wat Syne is, kom ons ook toe. Deur die geloof skou ons op Christus, nie van ver nie, maar ontvang ons Hom in ons $^{2}$ ).

Hierdie inwoning kan slegs geskied deur die Heilige Gees. Calvyn wys op die verskillende name waarmee die Gees in die Skrif genoem word. $\mathrm{Hy}$ is die Gees van aanneming tot kinders, die pand en sec̈l van ons erfenis, die ware salfolie, vuur, fontein. Alles dui daarop dat Christus in sekere sin werkeloos buite ons neerlê totdat ons harte op Hom gerig word deur die Gees ${ }^{\mathrm{a}}$ ).

Die geloofsgemeenskap tussen Christus en diegene wat aan Hom behoort, soos gewerk deur die Heilige Gees, is egter nie maklik te beskrywe nie. Calvyn beskry $\hat{\imath}$ dan die gemeenskap as 'n vereniging, bewerk deur die onmeetlike en bewonderenswaardige mag van Christus, waardeur ons met Hom saamgroei en met Hom waarlik verbind word soos die lede van die liggaam met die Hoof een liggaam vorm. $\mathrm{Ja}$, die uitverkorenes van God is almal in Christus so verbonde, dat hulle, net soos hulle aan één Hoof vassit, so ook as 't ware tot één liggaam saamgroei, so saam verbonde soos die lede van dieselfde liggaam; in waarheid één geword, daar hulle deur één geloof, hoop en liefde en deur dieselfde Gees saam leef, geroep nie alleen tot dieselfde erfenis van die ewige lewe nie maar ook tot die gemeenskap aan die één God en Christus").

Hierdie eenheid is 'n eenheid met Sy vlees en bloed, waarheen ook die instel- 
ling van die Nagmaal wys. Net soos die Nagmaal verklaar ook die Doop die lewensgemeenskap.

Deur die Doop word ons geroep tot die gemeenskap met die liggaam van Christus. Dit beteken die inlywing in die sigbare kerk van Christus. Daarmee beweer Calvyn nie dat die kinders voor hulle doop geen lid van die kerk was nie, maar by die doop betuig God ,publieklik" dat $\mathrm{Hy}$ hulle tot die gemeenskap van die kerk toelaat. Die gemeenskap kan dus wel voor die doop bestaan, maar by die doop word ons sigbaar geroep tot uitoefening van die geloofsgemeenskap in gemeenskap met die kerk. En by die salkrament van die Heilige Nagmaal onderhou ons die gemeenskap.

Die kerk as liggaam van Christus wat die Hoof is, het ten volle deel aan Christus, nie maar aan Sy gawes of Sy weldade nie, maar aan Homself, ook nie maar alleen aan Sy menslike natuur nie, maar aan die volle Christus as Middelaar.

Die gemeenskap met Christus dui Calvyn nader aan as 'n mistieke eenheid (unio mystica). Ons is met Christus een. In sy kommentaar op die brief aan die Efesiërs wys hy hierop met oortuiging. Calvyn spreek selfs van 'n substansiële vereniging. Daarmee kom hy nie op die spoor van Osiander nie, omdat hy voortdurend daarop wys dat dit geskied deur die werking van die Heilige Gees. Ons word deur die $\mathrm{krag}$ van die Heilige Gees ingelyf in die liggaam van Christus.

Gemeenskap van die heiliges.

Waar die wese van die kerk deur
Calvyn as die liggaam van Christus beskryf word, daar bring dit vanself mee dat die lede van die liggaam deur die een gemeenskaplike Hoof aan mekaar verbonde is. In die gemeenskap van die heiliges kom die liggaam van Christus wat volgens sy aard geestelik en verborge is, tot openbaring na buite. Die gemeenskap van die heiliges mag nie veronagsaam word nie, omdat dit baie goed die hoedanigheid van die kerk uitdruk. Want daardeur word gesê dat die heiliges tot die gemeenskap met Christus vergader word onder hierdie bepaling dat hulle alle weldade, wat God hulle verleen, aan mekaar wederkerig sou meedeel ${ }^{5}$ ). In dieselfde paragraaf sê hy verder: Immers, as hulle waarlik oortuig is dat God hulle gemeenskaplike Vader is, en Christus hulle gemeenskaplike Hoof, dan kan dit nie anders of, deur broederlike liefde verenig, hulle wederkerig aan mekaar sal meedeel wat aan elkeen behoort.

Vergewing van sondes.

Met so ' $n$ vaste oortuiging het Calvyn die kerk gesien as die liggaam van Christus dat hy daartoe gekom het om te konstateer dat buite die liggaam geen saligheid is en buite die kerk geen vergewing van sondes $n i^{6}$ ). Die vergewing verkry alleen die burgers en huisgenote. Die kerk moet egter eers gebou word, nie omdat daar enige kerk sonder vergewing kan wees nie, maar omdat die Here Sy barmhartigheid slegs in gemeenskap van die heiliges beloof het. Die vergewing van sondes, waarsonder ons geen verbond of gemeenskap met God het nie, is dus vir ons die eerste ingang tot die kerk en die koninkryk van $\mathrm{God}^{7}$ ). 
Met die ,eers” moet uiteraard nie aan tydsvolgorde gedink word nie, so asof ons eers ingelyf word in die kerk en daarna vergewing van sondes sou ontvang nie. Die inplanting in die liggaam is self die vergewing ${ }^{9}$ ).

Sonder vergewing kan ons nie bestaan voor God nie, en die weldaad is soseer die eiendom van die kerk dat ons dit nie anders kan geniet nie as wanneer ons in haar gemeenskap bly ).

Konklusie.

Ons sien dus nou reeds hoe Calvyn die kerk beskou het. Dit was vir hom geen vormlose, vaagomlynde liggaam, bloot toevallige saamvergadering van individue, en liggies geassosieer as gevolg van gemeenskaplike opvattings of simpatië nie. Dit was nie 'n instelling ten opsigte waarvan mens 'n houding van onverskilligheid kan inneem of waartoe 'n belydende Christen mag weier om te behoort nie. Want om daarbuite te staan was om jouself af te sny van die huis van God waarin $\mathrm{Hy}$ die brood van die lewe bewaar. Die kerk was immers vir Calvyn die sfeer waarin die genade van God eksklusief werksaam is. Dit was die enige bewaarder en uitdeler van die seëninge van die Evangelie, wat andersins onbekombaar is $\left.^{10}\right)$.

Die kerk was vir hom die liggaam van Christus.

IV. Sigbare en onsigbare kerk.

Daar was by Calvyn 'n kenlike ontwikkeling in sy beklemtoning van die sigbare kerk. Waar hy in sy vroeëre geskrifte veral gehandel het oor die onsigbare kerk, het hy in die finale uitgawe van sy Institusie in 1559 veral die sigbare kerk op die oog gehad. Dat hy dit al hoe meer beklemtoon het is te verstaan as mens dit teen die agtergrond sien van sy stryd teen die Roomse $\mathrm{Kerk}^{11}$ ). Ons bemerk hierdie ontwikkeling bv. baie duidelik t.o.v. die stelling wat in die vorige paragraaf behandel is nl. „buite die kerk geen saligheid nie $\left.^{12}\right)$. Kenlik het Calvyn dit in sy vroeëre geskrifte laat slaan op die onsigbare kerk, op die vergadering van uitverkorenes, op die kongregasie van die ware Christgelowiges onder die Hoof Christus. Ook in die standaardedisie van die Institusie van 1559 het hy dit nie teruggeneem nie, maar aan die ander kant laat hy dit in genoemde uitgawe ook slaan op die sigbare kerk as die moeder van die gelowiges ${ }^{13}$ ).

Baie duidelik onderskei Calvyn tussen die onsigbare en die sigbare openbaring van die liggaam van Christus. Uitgangspunt bly natuurlik die grondgedagte van die kerk as liggaam van Christus.

Maar nou is daar 'n onsigbare en 'n sigbare, 'n inwendige en uitwendige kant. Dit is nie twee kerke nie. Dit sou in flagrante stryd wees met die grondgedagte van die kerk as die liggaam van Christus. Die liggaam van Christus is een maar dit het 'n kant soos dit hom na buite openbaar en 'n kant wat alleen voor Gods oë toeganklik is.

Die wese van die kerk is nou die onsigbare band aan Christus soos die wese van die mens sy siel is. In waarheid dek die twee mekaar geheel en al, maar ons mense beskou baie keer sommige tot lid van die liggaam, die sigbare kerk dus, wat in waarheid geen lede is nie en in geen organiese verband staan met die Hoof van die liggaam nie ${ }^{14}$ ). 
Die opvatting van Calvyn oor die onsigbare en sigbare kerk kom ten duidelikste na vore in die volgende sitaat: Die Heilige Skrif spreek in tweërlei sin van die kerk. Soms, wanneer dit die kerk noem, bedoel dit die kerk, waarin geen ander opgeneem word as hulle wat deur die genade van die aanneming tot kinders van God en deur die heiligmaking van die Gees waaragtige lede van Christus is nie. En dan bevat dit nie alleen die heiliges wat op aarde woon nie maar alle uitverkorenes, wat daar van die begin van die wêreld gewees het.

Dikwels egter dui die Skrif met die naam kerk aan die hele menigte van mense, wat oor die aarde versprei is, en wat bely, dat hulle één God en Christus dien, deur die Doop in Sy verbond ingelyf is, deur die deelneming aan die Nagmaal hulle eenheid in die ware leer en liefde betuig, eenstemmigheid het in die Woord van die Here en tot die prediking daarvan die diens onderhou wat deur Christus ingestel is. In hierdie kerk egter is daar baie huigelaars gemeng wat niks van Christus het behalwe die naam en uiterlike skyn nie. Baie eergieriges, hebsugtiges, afgunstiges, kwaadsprekers, sommige van 'n onrein lewe, wat 'n tydlank verdra word omdat hulle nie deur 'n wettige oordeel oortuig kan word nie of omdat nie altyd 'n behoorlike gestrengheid van tug heers nie.

Net soos wat dit dus nodig is dat ons aan 'n onsigbare, alleen voor Gods oë waarneembare, kerk glo so word ons gebied om dit, wat ten aansien van mense kerk genoem word, hoog te ag en daarmee gemeenskap te oefen ${ }^{15}$ ).
Die kerk na sy wese is die onsigbare kerk, die kerk na sy verskyning of uitwendige openbaring is die sigbare kerk. In laasgenoemde is daar baie kaf onder die koring, baie hipokriete. Van die hipokriete geld dat hulle wel uit die skoot van die kerk voortkom maar hulle kan nooit die wese, die karakter van die kerk bepaal nie en in der waarheid behoort hulle nooit werklik tot die kerk nie ${ }^{10}$ ).

Aan die ander kant bevat die onsigbare kerk almal wat God van ewigheid af uitverkies het en wat geleef het van die begin van die wêreld af, ook hulle wat geen historiese kennis van Christus gehad het nie ${ }^{17}$ ).

In die woorde van Calvyn kom dit hierop neer: Dus is volgens die verborge predestinasie van God soos Augustinus sê, baie skape buite en baie wolwe binne. Alleen sy oë sien, wie van hulle wat openlik Sy tekens dra, sonder veinsery heilig is en tot die einde toe sal volhard: wat die vernaamste is in die saligheid ${ }^{18}$ ).

Aan die sigbare kerk, die oponbaring van die liggaam van Christus na buite, wy Calvyn dan besondere aandag in die Institusie van 1559. Hy wys daarop dat die kerk bepaalde kenmerke het.

\section{Kenmerke van sigbare kerk.}

Ook hier kan ek Calvyn self laat spreek: As tekens waardeur die kerk geken kan word, het ons die prediking van die Woord en die onderhouding van die Sakramente gestel. Want hierdie twee kan nêrens plaasvind sonder dat dit vrug dra en deur Gods seën voorspoedig gemaak word nie. Ek sê nie, dat oral waar die Woord verkondig word, terstond vrug ontstaan nie, maar ek sê dat dit nêrens ontvang word en 
'n vaste setel het tensy om sy kragtige werking te toon nie. Hoe dit ook sy, waar die prediking van die Evangelie gehoor word en die Sakramente nie veronjgsaam word nie, daar vertoon hom vir 'n tyd 'n geensins bedrieglike nog twyfelagtige gedaante van die kerk. Om haar gesag te verag, vermaninge te verwerp, raadslae te weerstreef of kastydinge te bespot staan niemand vry nie; veel minder van haar af te wyk en haar eenheid te verbreek. Want die Here heg aan die gemeenskap van Sy kerk so grote waarde, dat $\mathrm{Hy}$ hom vir 'n oorloper en verlater van die godsdiens hou, wat hom van elke Christelike vergadering, wat die ware bediening van die Woord en Sakramente onderhou, hardnekkig vervreem. Hy prys haar gesag soseer aan, dat $\mathrm{Hy}$, wanneer dit geskend word, dit daarvoor hou dat Sy eie gesag verminder is. Immers, dit is van geen geringe betekenis nie, dat die kerk genoem word die pilaar en vastigheid van die waarheid en die huis van God (1 Tim. 3:15). Met hierdie woorde gee Paulus te kcnne, dat die kerk, opdat die waarheid van God nie verlore gaan op die wêreld nie, sy getroue bewaakster is, omdat God deur die diens en werksaamheid van die kerk die suiwere prediking van Sy Woord wou bewaar en Hom jeens ons as 'n Huisvader wou betoon deurdat $\mathrm{Hy}$ ons met geestelike spyse voed en sorg vir alles wat nuttig is tot ons saligheid. Dit is ook geen gewone lof nie dat van die kerk gesê word dat dit deur Christus verkies en afgesonder is tot bruid, om te wees sonder vlek of rimpel, Sy liggaam en vervulling (Ef. 1:23; 5:27). Daaruit volg dat om uit die kerk weg te gaan beteken verloëning van God en Christus. Daarom moet ons ons des te meer hoed vir so ' $n$ misdadige skeiding. Want deurdat ons, vir sover ons kan, die ondergang beraam van Gods waarheid, is ons waardig dat $\mathrm{Hy}$ met die ganse geweld van Sy toorn sou bliksem om ons te verpletter. En daar kan geen vreesliker misdaad bedink word nie as met heiligskennende troueloosheid die huwelik te skend, wat die eniggebore Seun van God Hom verwerdig het om met ons aan te gaan $^{10}$ ).

Aan genoemde kenmerke, nl. die suiwere bediening van Woord en Sakramonte, verbind Calvyn ook sy stelling dat die Roomse Kerk geen reg het op die naam van kerk nie. Hy betoon wel geweldig veel verdraagsaamheid as hy daarop wys dat die gemeenskap wat die kenmerke vertoon veilig as 'n ware kerk aanvaar moet word ook al is dit origens vol van foute ${ }^{30}$ ).

Maar wat die Roomse Kerk betref sê hy dan: Sodra in die vesting van die religie die leuen binnegedring het, die hoofsaak van die noodsaaklike leer verbaster is en die gebruik van die Sakramente terneergestort het, volg ongetwyfeld die ondergang van die kerk, net soos dit met die lewe van 'n mens gedaan is wanneer sy nek deurboor is of sy ingewande dodelik gewond is. Die kerk moet noodsaaklik ineenstort, wanneer die hoofsom van die religie wegval, wat haar alleen kan staande hou. Bowendien, waar die ware kerk die pilaar en vastigheid van die waarheid is (1 Tim. 3:15), daar is dit seker dat daar geen kerk is waar die leuen en die valsheid die ryk ingeneem het nie. 
En daar die saak so staan onder die pousdom, kan mens begryp, wat vir 'n kerk daar nog oor is. In plek van die bediening van die Woord regeer daar ' $n$ verkeerde en uit leuens saamgesmede bewind, wat die suiwere lig deels uitblus, deel verstik. In plek van die Nagmaal van die Here het daar 'n baie skandelike heiligskennis gekom. Die diens van God is deur 'n veelsoortige en ondraaglike menigte van superstisies misvorm. Die leer, waarsonder die Christendom nie bestaan nie, is geheel en al begrawe en verdryf. Die openbare samekomste is skole van afgodery en goddeloosheid. Daarom is daar geen gevaar, dat ons, deur af te wyk van die verderflike deelgenootskap aan soveel skanddade, van die kerk van Christus sou afgeskeur word nie ${ }^{21}$ ).

By hierdie twee kenmerke van die ware kerk, nl. die suiwere bediening van die Woord en die Sakramente, voeg Calvyn nog 'n derde, hoewel hy dit later in behandeling bring, nl. die handhawing van die tug.

Daarop wys ook Hunter as hy sê:

„But along with these he was accustomed to add a third, namely, the exercise of a vigilant discipline",22).

Ten onregte word dit dus beweer dat Calvyn alleen maar twee kenmerke vir die ware kerk erken het. Dit word duidelik as ons Calvyn hoor sê: Net soos die saligmakende leer van Christus die siel van die kerk is, so vorm die tug in die kerk die senuwees, waardeur dit geskied dat die lede van die liggaam, elk op sy plek, met mekaar verbonde is. Daarom soek almal, wat die tug wil wegneem of die herstel daarvan wil ver- hinder, hetsy hulle dit doen met opset hetsy uit onnadenkendheid, ongetwyfeld die uiterste verstrooiing van die kerk. Die tug is dus as 't ware die toom (breidel) waardeur diegene in toom gehou en getem word wat teen die leer van Christus woed, of die prikkel waardeur hulle wat nie gewillig genoeg is, opgewek word; soms is dit ook soos die vaderlike tugroede waarmee op sagmoedige wyse en in ooreenstemming met die sagsinnigheid van die Gees van Christus, diegene gekasty word, wat dieper geval het ${ }^{23}$ ).

\section{Die kerk en die koninkryk van God.}

Van baie groot belang is dat Calvyn die kerk in 'n sekere sin gelykstel met die koninkryk van God. Die wese van die ryk is net soos die van die kerk onsigbaar en geestelik. Ook by die koninkryk geld dit dat die burgers verstrooid kan wees en die ryk na sy uiterlike verskyning ontbonde, maar tog is dit daar en bly dit onbeweeglik. Die ingang tot die ryk is net soos by die kerk die vergewing van sondes. Die kinders van die verbond, wat as lede van die kerk gebore is, is ook reeds by hulle geboorte burgers van die ryk.

Dit kom eintlik daarop neer dat die kerk, wat die liggaam van Christus is, as dit gesien word onder die aspek van die koningskap van Christus, terselfdertyd die Koninlryk van God is ${ }^{21}$ ).

Van belang is nou egter dat Calvyn die verhouding nou verder so sien dat die ryk van God hom verder uitstrek as die sigbare instituut van die kerk. Dit word oral gevind waar Christus as Koning erken word en waar volgens Sy ordinansies geleef word. Calvyn iden- 
tifiseer dus die ryk van God met die kerk, maar dan nie met die kerk in institutêre vorm nie.

Richel wys in sy proefskrif daarop ${ }^{25}$ ) dat ons hier by Calvyn reeds aantref die onderskeid wat later deur A. Kuyper kragtig na vore gebring is, nl. tussen die kerk as organisme en die kerk as instituut.

Die liggaam van Christus openbaar hom in die instituut van die kerk met sy amptelike dienste, maar dit openbaar hom ook buite die instituut, $\mathrm{nl}$. oral waar gelowiges gevind word, wat of indiwidueel of in organisasieverband optree.

Die identiteit tussen ryk van God en die kerk is onmiskenbaar aan te wys met die verskil alleen dat die hoofgedagte wat op die voorgrond tree by die kerk die liggaam is waarvan Christus die Hoof is, terwyl dit by eersgenoemde 'n ryk is waarvan Christus die Koning is. Die lede van die liggaam vorm die skare wat onder Christus as Koning stry.

Die sentrum, die hart van die ryk moet ons soek in die geinstitueerde kerk, met die bediening van die Woord en Sakramente. Die ryk self is egter van universele betekenis en bestryk alle lewensgebiede. Ons Koning regeer ons op geestelike wyse deur Sy Woord en rees.

Aan Christus is ook nie maar net die lewe van die enkeling onderworpe nie maar ook die georganiseerde gemeenslrapslewe nl. die gesin, familie, skool, maatskappy en staat, ens. Op alle kulturele goedere en gawes lê Christus beslag en aan die gelowiges as Sy krygsknegte stel $\mathrm{Hy}$ die eis om al hulle gawes te gebruik tot die eer van God.

In Genćve het Calvyn hierdie beginsels in die praktyk gebring. Dit was vir hom dus geen in die lughangende spekulasies nie maar lewende werklikheid. Met sy handelwyse het hy geensins alle lewensterreine verkerklik en dit onder die instituut van die kerk ingeskakel nie. „Theoretisch en practisch was hij diartoe slechts in staat door tusschen het organisme en het instituut der kerk te onderscheiden, zonder daarmede echter den band tusschen beide door te snijden",20).

\section{S. C. W. DUVENAGE.}

\section{Potchefstroom}

1) A. MITCHELL HUNTER: The teaching of Calvin; James Clarke \& Co., London, 1950, p. 152.

2. JOHANNES CALVIN: Institutie, Vertaling deur A. Sizoo, III, 1,4; Meinema, Delft, Z. J.

3. Institutie, III, 1,3

4. Institutie IV, 1,2 .

5. Institutie IV, 1,3

6. Institutie IV, 1,20 .

7. Ibid.

8. P. J. RICHEL: Het kerkbegrip van Calvyn; Utrecht, 1942; p. 59

9. Institutie IV, I,22

10. A. MITCHELL HUNTER: a.w., p. 153

11. TH. WERDERMANN: Calvins Lehro von der Kirche in ihre gesehichtlichen Entwicklung, in Calvinstudien; Leipzig, 1909; p. 317.

12. A. D R POLMAN: Onze Nederlandsche Geloofsbelijdenis, III; Wever, Franeker s.j.; p. 291.

13. Institutie IV, I, 2-4

14. RICHEL: a.w. p. 63

15. Institutie IV, I,7; vgl. POLMAN, a.w. p. 266

16. RICHEL; a.w., p. 62

117. HUNTER: a.w., p. 156

18. Institutie IV, 1,8

19. Institutie IV, I,10

20. Institutie IV, 1,12; vgl. ook volgende paragrawe.

21. Institutie IV, II, 1 en 2.

22. HUNTER, a.w., p. 156.

23. Institutie IV, XII,1.

24. RICHEL: a.w., p. 73.

25. RICHEL: a.w., p. 75

'6. RICHEL: a.w., p. 78. 